06.1

\title{
Состав, электронное и атомное строение наночастиц палладия при различных концентрациях металла в матрице полиэтилена
}

\author{
() С.С. Подсухина ${ }^{1}$, А.В. Козинкин ${ }^{1}$, В.Г. Власенко ${ }^{1}$, Г.Ю. Юрков ${ }^{2}$, О.В. Попков ${ }^{3}$ \\ ${ }^{1}$ Научно-исследовательский институт физики Южного федерального университета, Ростов-на-Дону, Россия \\ ${ }^{2}$ Институт общей и неорганической химии им. Н.С. Курнакова РАН, Москва, Россия \\ ${ }^{3}$ Московский государственный технический университет им. Н.Э. Баумана, Москва, Россия \\ E-mail: svetlanapodsukhina@gmail.com
}

Поступило в Редакцию 12 июля 2019г.

В окончательной редакции 26 декабря 2019 г.

Принято к публикации 26 декабря 2019г.

Состав, электронное и атомное строение наночастиц палладия, стабилизированных в полиэтилене высокого давления (с концентрацией палладия 10 и 20 mass \%), исследованы методами просвечивающей электронной микроскопии, рентгеновской дифракции и рентгеновской спектроскопии поглощения. Установлено, что наночастицы состоят из металлического $(\mathrm{Pd})$ и оксидного $\left(\mathrm{Pd}_{2} \mathrm{O}_{3}\right)$ компонентов, а со снижением концентрации металла уменьшаются их средний размер (от 7 до $6 \mathrm{~nm}$ ) и координационные числа в Pd-сфере (от 7 до 5.7).

Ключевые слова: наночастицы, композитные материалы, полиэтилен высокого давления, EXAFS-спектры.

DOI: 10.21883/PJTF.2020.07.49214.17978

Композитные материалы с наночастицами палладия составляют основу разнообразных катализаторов, используемых в различных областях: от крекинга нефти, производства ацетилена, аммиака, хлора, серной и азотной кислот и т.д. до производства автомобильных катализаторов и топливных элементов [1], которые позволяют не только резко уменьшить выброс вредных веществ в атмосферу от двигателей внутреннего сгорания, но и увеличить их КПД до $90 \%$ в отличие от традиционных энергоустановок. В обзорной работе [1] отмечается, что исследований наночастиц $\mathrm{Pd}$ по сравнению с исследованиями наночастиц других металлов существенно меньше и они носят фрагментарный характер. Дальнейшее улучшение характеристик применяемых катализаторов, увеличение их активности при уменьшении количества палладия за счет создания композитов с наночастицами позволит уменьшить себестоимость катализаторов палладия. Такой подход невозможен без разработки простых и экономичных методов получения композитных материалов с наночастицами палладия.

Электронная структура наночастиц Pd чувствительна как к внутренним (размер частиц, их морфология и структура), так и к внешним факторам, особенно связанным с зарядовыми эффектами [2]. При этом исследований электронного и атомного строения композитных материалов с наночастицами $\mathrm{Pd}$ крайне мало. Например, для наночастиц $\mathrm{Pd}$, нанесенных на поли(тетра)фторэтиленовые микрогранулы, на основе анализа температурно-зависимых EXAFS Pd $K$-краев поглощения (EXAFS - дальняя тонкая структура рентгеновских спектров поглощения) в [3] определены параметры ангармоничности межатомного потенциала в наночастицах $\mathrm{Pd}$ и рассчитаны температура плавления
$\left(T_{\text {melt }}=1591 \mathrm{~K}\right)$ и температура Дебая $\left(\Theta_{\mathrm{D}}=257 \mathrm{~K}\right)$, которые оказались значительно меньше, чем в металлическом палладии: 1825 и $277 \mathrm{~K}$ соответственно. Исследование наночастиц гидрида палладия совместно методами XRPD (рентгеновская порошковая дифракция) и EXAFS позволило [4] отдельно проанализировать структуру ядра и поверхностной оболочки, которая является аморфной, и доказать, что расстояние $\mathrm{Pd}-\mathrm{Pd}$ в аморфной оболочке наночастиц значительно короче, чем в объемном структурированном ядре, что является важным для понимания каталитических свойств поверхности наночастиц Pd. Исследование методами XANES (ближняя тонкая структура рентгеновских спектров поглощения) и EXAFS показало [5] различное образование карбидов палладия в объеме ядра и на поверхности наночастиц и позволило установить изменение числа связей $\mathrm{Pd}-\mathrm{C}$ при каталитических реакциях в поверхностной области этих наночастиц.

Цель настоящей работы - создание новых композитных материалов с наночастицами $\mathrm{Pd}$, локализованными внутри полиэтилена высокого давления (ПЭВД), и исследование состава, электронного и атомного строения и их изменений при различной концентрации $\mathrm{Pd}$ в ПЭВД.

Композитные материалы с Рd-содержащими наночастицами в ПЭВД получены термическим разложением [6,7] металлсодержащего соединения (МСC), такого как диацетат палладия $(\mathrm{II})-\mathrm{Pd}\left(\mathrm{CH}_{3} \mathrm{COO}\right)_{2}$, в расплаве ПЭВД с углеводородным маслом (раствор-расплав). $\mathrm{B}$ качестве растворителя $\mathrm{Pd}\left(\mathrm{CH}_{3} \mathrm{COO}\right)_{2}$ использовался $\mathrm{CHCl}_{3}$. Были синтезированы два образца с концентрацией палладия 10 и 20 mass \%. Диацетат палладия

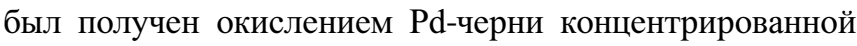


Структурные данные локального атомного окружения атомов $\mathrm{Pd}$, полученные из двухсферной подгонки EXAFS $(R-$ межатомные расстояния, $N$ - координационное число, $\sigma^{2}-$ фактор Дебая-Валлера, $Q-$ функция качества подгонки)

\begin{tabular}{c|c|c|c|c|c}
\hline Соединение & $N$ & $R, \AA$ & $\sigma^{2}, \AA^{2}$ & $\mathrm{KC}$ & $Q, \%$ \\
\hline Рd-фольга & 12 & 2.75 & 0.0065 & $\mathrm{Pd}$ & $2.0^{*}$ \\
ПЭ-Pd(10 mass \%) & 1.8 & 1.93 & 0.0040 & $\mathrm{O}$ & $12^{* *}$ \\
& 5.7 & 2.75 & 0.0067 & $\mathrm{Pd}$ & \\
ПЭ-Pd(20 mass \%) & 1.7 & 1.96 & 0.0040 & $\mathrm{O}$ & $7.5^{* *}$ \\
& 7 & 2.74 & 0.0067 & $\mathrm{Pd}$ &
\end{tabular}

${ }^{*}$ Окно $r=2.0-2.9 \AA$.

** Окно $r=1.0-3.0 \AA$.

$\mathrm{HNO}_{3}$ в среде ледяной уксусной кислоты:

$\mathrm{Pd}+\mathrm{HNO}_{3}+\mathrm{CH}_{3} \mathrm{COOH} \rightarrow \mathrm{Pd}\left(\mathrm{CH}_{3} \mathrm{COO}\right)_{2}+\mathrm{NO}_{2}+\mathrm{H}_{2} \mathrm{O}$.

Процесс термического разложения раствора диацетата палладия в хлороформе проводили при температуре $300^{\circ} \mathrm{C}$ в атмосфере аргона при интенсивном перемешивании, поддерживая постоянную температуру. С помощью капельной воронки в раствор-расплав полиэтилен-масло по каплям вводили раствор МСС со скоростью $30 \mathrm{ml} / \mathrm{h}$. Скорость подачи аргона регулировалась таким образом, чтобы обеспечить быстрое удаление газообразных продуктов. После добавления всего раствора МСС реакционную массу выдерживали в течение $1 \mathrm{~h}$ при температуре синтеза, поддерживая интенсивное перемешивание. Затем нагрев прекращался, и реакционная смесь охлаждалась до комнатной температуры в атмосфере аргона. После отмывки образцов от масла гексаном в аппарате Сокслета образцы высушивались и хранились до начала исследований на воздухе. Таким образом, были синтезированы образцы с концентрацией металлсодержащего компонента 10 и 20 mass \%.

Для определения состава композитных наноматериалов был проведен рентгенофазовый анализ на рентгеновском дифрактометре ДРОН-3 $\left(\mathrm{Cu} K_{\alpha}\right.$-излучение, графитовый монохроматор). Полученные дифрактограммы сравнивались с базой данных PDF2 международного комитета JCPDS от 2004 г.

Размер частиц был определен методом просвечивающей электронной микроскопии (ПЭМ) с использованием микроскопа фирмы JEOL JEM-1011 при ускоряющем напряжении $80 \mathrm{kV}$. Предварительно образец подвергался ультразвуковому диспергированию в гексане, а образовавшаяся дисперсия наносилась на медную сетку, покрытую углеродом.

Атомное и электронное строение наночастиц Pd было исследовано методом рентгеновской спектроскопии поглощения. Рентгеновские $\mathrm{Pd} L_{3}$-края поглощения получены в режиме пропускания на EXAFS-спектрометре станции структурного материаловедения в Курчатовском синхротронном центре (Москва) при энергии электронного пучка $2.5 \mathrm{GeV}$ и токе $80 \mathrm{~mA}$. Использовался двухкристальный $\mathrm{Si}(111)$-монохроматор. Обработка спектров осуществлялась путем стандартных процедур выделения фона, нормирования на величину скачка $L_{3}$-края и выделения атомного поглощения $\mu_{0}$ [8]. Фурье-преобразование EXAFS $(\chi)$-спектров выполнено в интервале волновых векторов фотоэлектронов $\mathbf{k}$ от 3.0 до $14.0 \AA^{-1}$ с весовой функцией $k^{3}$. Полученные модули фурье-трансформант (МФТ) представляли собой псевдорадиальное распределение атомов ближайших координационных сфер (КС) без фазовой поправки. Пороговая энергия ионизации $E_{0}$ выбиралась по значению максимума первой производной $L_{3}$-края и в дальнейшем варьировалась при подгонке. Количественные характеристики ближайшего окружения атомов палладия в образцах определялись путем нелинейной подгонки структурных параметров (межатомные расстояния, координационные числа (КЧ), фактор Дебая-Валлера $\left(\sigma^{2}\right)$ ) соответствующих КС при сопоставлении рассчитанного EXAFS-сигнала и выделенного из полного EXAFS методом фурье-фильтрации с использованием пакета программ IFFEFIT-1.2.11 [9]. Поскольку КЧ и фактор Дебая-Валлера - сильно коррелируемые параметры, при определении КЧ параметр $\sigma^{2}$ был фиксированным. Необходимые для построения модельного спектра фазы и амплитуды рассеяния фотоэлектронной волны рассчитывались с помощью программы FEFF7 [10] с использованием атомных координат для fсс-палладия [11].

Дифрактограммы композитов с концентрацией палладия 10 и 20 mass \% аналогичны, поэтому на рис. 1 представлена только одна дифрактограмма композита с концентрацией палладия 10 mass \%, на которой наблюдаются характерные максимумы $\mathrm{Pd}$ и $\mathrm{Pd}_{2} \mathrm{O}_{3}$. Bce peфлексы согласуются с данными базы PDF2 международного комитета JCPDS и свидетельствуют о том, что наночастицы состоят из металлического $\mathrm{Pd}$ и оксида

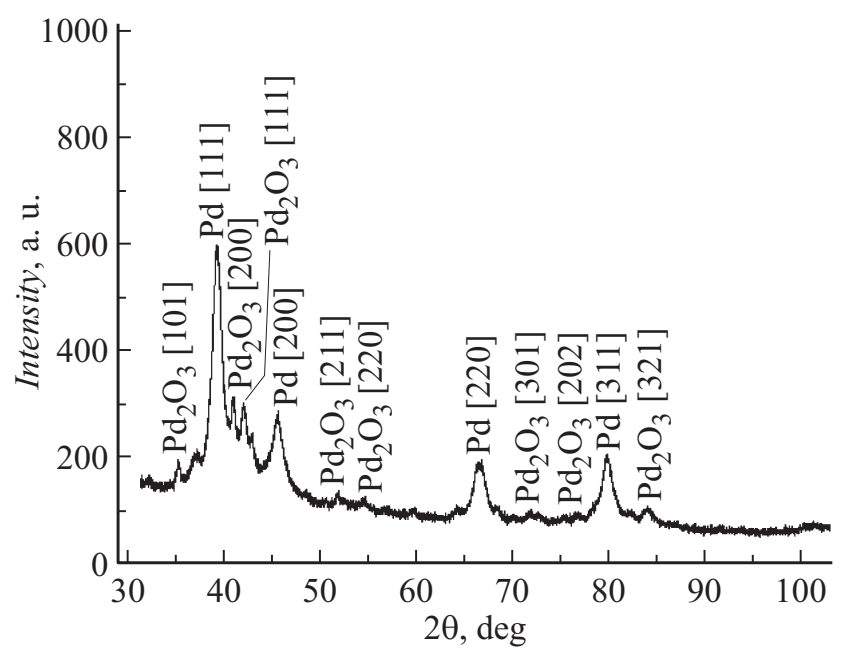

Рис. 1. Дифрактограмма нанокомпозита с содержанием $\mathrm{Pd}$ в ПЭВД 10 mass \%. 
$\mathrm{Pd}_{2} \mathrm{O}_{3}$, а также о том, что наночастицы $\mathrm{Pd}$ имеют сформированную кристаллическую структуру.

На рис. 2 приведена ПЭМ-микрофотография образца с концентрацией 10 mass \% Pd. Для образца с 20 mass \% $\mathrm{Pd}$ ПЭМ-микрофотография аналогичная, но концентрация наночастиц $\mathrm{Pd}$ в ПЭВД вдвое больше. Средний размер наночастиц, определенный исходя из анализа ПЭМ-микрофотографий, изменялся от 7 до $6 \mathrm{~nm}$ при уменьшении концентрации металла в образцах от 20 до 10 mass $\%$.

MФT EXAFS Pd $L_{3}$-краев металлической фольги Pd, образцов с содержанием 10 и 20 mass \% Pd приведены на рис. 3. Все МФТ содержат основной пик при $r=2.50 \AA$ (без учета фазового сдвига), соответствующий наименьшему расстоянию $\mathrm{Pd}-\mathrm{Pd}$ в гранецентрированной кубической структуре. Амплитуда этого пика уменьшается при переходе от металлической фольги к наночастицам $\mathrm{Pd}$ и с уменьшением концентрации $\mathrm{Pd}$ в нанокомпозитах от 20 до 10 mass \%.

B MФТ EXAFS образцов с различной концентрацией $\mathrm{Pd}$ также присутствуют пики с меньшими $r$, которые с учетом данных рентгеновской дифракции указывают на образование окисленной фазы Pd. Нами построена модель наночастиц, состоящих из смеси оксида и металлического Pd. Параметры локального атомного строения, полученные для такой наилучшей модели, приведены в таблице. Радиус КС в наночастицах, соответствующий расстоянию $\mathrm{Pd}-\mathrm{Pd}$, с точностью погрешности эксперимента согласуется со значением, характерным для fсc-структуры. КЧ в наночастицах меньше по сравнению с КЧ в Рd-фольге и равны 7 и 5.7 при уменьшении содержания Pd от 20 до 10 mass \%. Ближайшие КС, состоящие из атомов кислорода, имеют радиусы 1.93 и $1.96 \AA$ (см. таблицу), значения которых меньше, чем в стабильном $\mathrm{PdO}(\sim 2.10 \AA)$, но близки к значению $1.963(9) \AA$ в $\mathrm{KPd}_{2} \mathrm{O}_{3}[12]$, содержащем $\mathrm{Pd}^{2+}$ и $\mathrm{Pd}^{4+}$, что хорошо согласуется с данными XRPD.

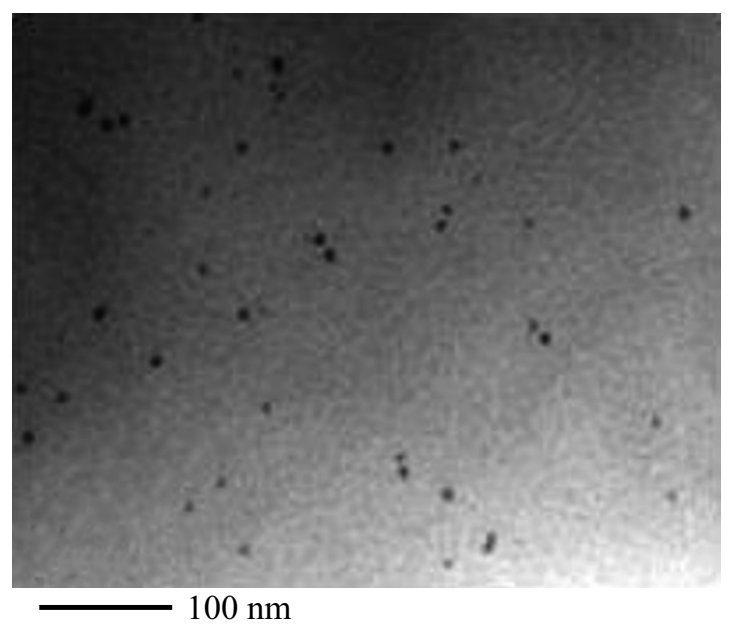

Рис. 2. Микрофотография нанокомпозита с концентрацией $\mathrm{Pd}$ в ПЭВД 10 mass \%.
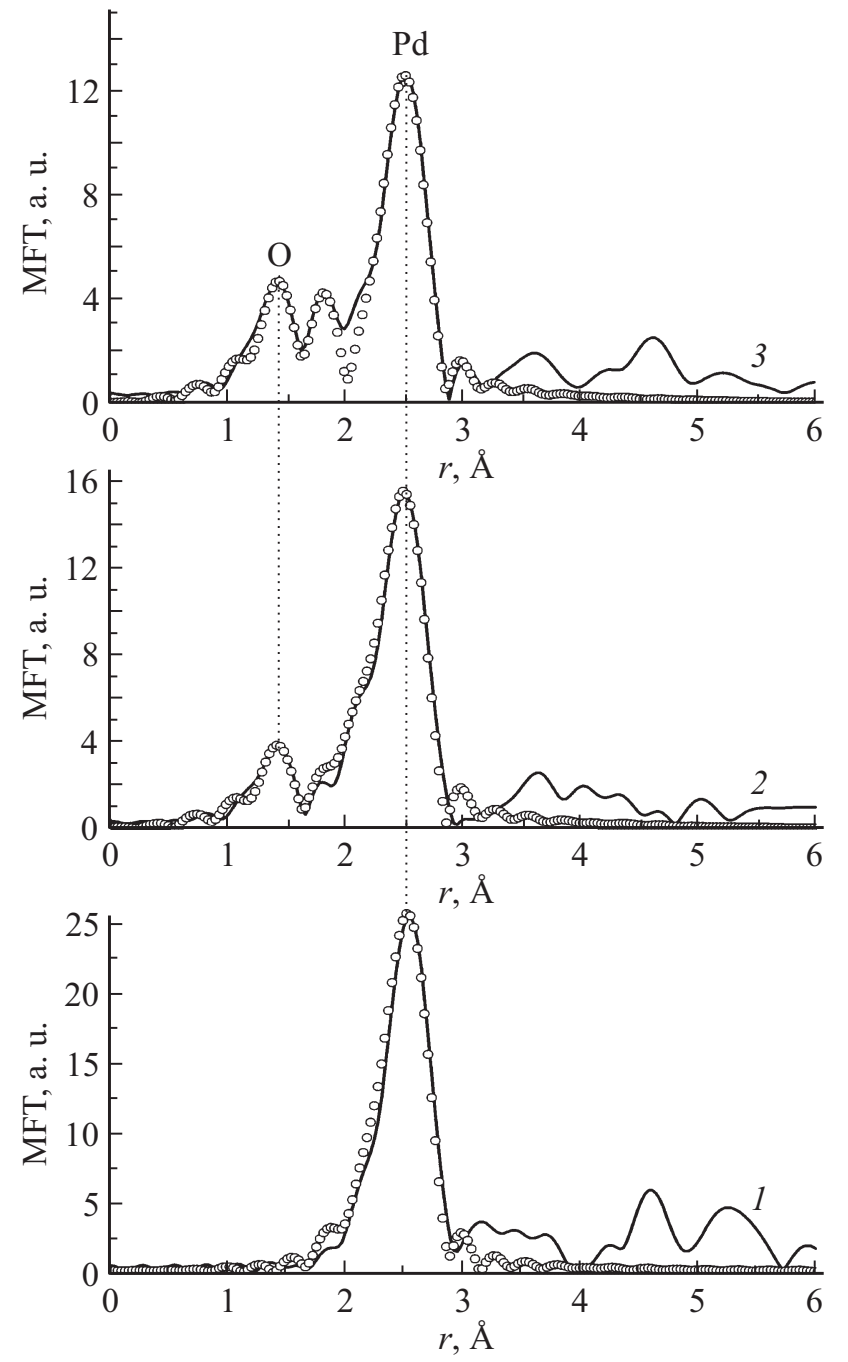

Рис. 3. МФT EXAFS Pd $L_{3}$-краев металлической фольги Pd (1), образцов нанокомпозитов с содержанием Рd в ПЭВД 20 (2) и 10 mass \% (3). Точки - теория, сплошная линия эксперимент.

Таким образом, наночастицы $\mathrm{Pd}$, полученные в матрице ПЭВД в результате разложения диацетата палладия при $300^{\circ} \mathrm{C}$, содержат как металлическую $(\mathrm{Pd})$, так и оксидную фазы палладия, причем с уменьшением концентрации металла в полимерной матрице уменьшаются средний размер наночастиц (от 7 до $6 \mathrm{~nm}$ ) и КЧ в Pd-cфере (от 7 до 5.7).

\section{Финансирование работы}

Работа выполнена в рамках реализации базовой части госзадания в сфере научной деятельности (проект 3.6105.2017/8.9).

\section{Конфликт интересов}

Авторы заявляют, что у них нет конфликта интересов. 


\section{Список литературы}

[1] Губин С.П., Юрков Г.Ю., Катаева Н.А. Наночастицы благородных металлов и материалы на их основе. М.: ООО „Азбука-2000“, 2006. 156 с.

[2] Drings H., Viswanath R.N., Kramer D., Lemier Ch., Weissmüller J. // Appl. Phys. Lett. 2006. V. 88. P. 253103 (1-3). DOI: $10.1063 / 1.2216897$

[3] Власенко В.Г., Подсухина С.С., Козинкин А.В., Зубавичус Я.В. // ФТТ. 2016. Т. 58. В. 2. С. 409-414. DOI: $10.1134 / \mathrm{S} 1063783416020335$

[4] Bugaev A.L., Guda A.A., Lomachenko K.A., Shapovalov V.V., Lazzarini A., Vitillo J.G., Bugaev L.A., Groppo E., Pellegrini R., Soldatov A.V., van Bokhoven J.A., Lamberti C. // J. Phys. Chem. C. 2017. V. 121. P. 18202-18213.

DOI: $10.1021 /$ acs.jpcc.7b04152

[5] Bugaev A.L., Usoltsev O.A., Guda A.A., Lomachenko K.A., Pankin I.A., Rusalev Yu.V., Emerich H., Groppo E., Pellegrini R., Soldatov A.V., van Bokhoven J.A., Lamberti C. // J. Phys. Chem. C. 2018. V. 122. P. 12029-12037. DOI: $10.1021 /$ acs.jpcc.7b11473

[6] Gubin S.P., Yurkov G.Yu., Kosobudsky I.D. // Int. J. Mater. Product Technol. 2005. V. 23. P. 2-25. DOI: 10.1504/IJMPT.2005.006587

[7] Yurkov G.Yu., Fionov A.S., Popkov O.V., Kosobudskii I.D., Taratanov N.A., Potemkina O.V. // Advances in composite materials for medicine and nanotechnology / Ed. B. Attaf. InTech, 2011. P. 343-364. DOI: 10.5772/14881

[8] Кочубей Д.И., Бабанов Ю.А., Замараев К.И., Ведринский Р.В., Крайзман В.Л., Кулипанов Г.Н., Мазалов Л.Н., Скринсккй А.Н., Федоров В.К., Хельмер Б.Ю., Шуваев A.T. Рентгеноспектральный метод изучения структуры аморфных тел: EXAFS-спектроскопия. Новосибирск: Наука, 1988. $306 \mathrm{c}$.

[9] Newville M. // J. Synchrotron Rad. 2001. V. 8. P. 96-100. DOI: $10.1107 /$ S0909049500016290

[10] Zabinski S.I., Rehr J.J., Ankudinov A., Alber R.C. // Phys. Rev. B. 1995. V. 52. P. 2995-3009. DOI: 10.1103/PhysRevB.52.2995

[11] Höglund J., Fernández Guillermet A., Grimvall G., Körling M. // Phys. Rev. B. 1993. V. 48. P. 11685-11691. DOI: 10.1103/PhysRevB.48.11685

[12] Panin R.V., Khasanova N.R., Bougerol C., Schnelle W., Van Tendeloo G., Antipo E.V. // Inorg. Chem. 2010. V. 49. P. 12951297. DOI: $10.1021 / \mathrm{ic} 902187 \mathrm{a}$ 